\title{
The Reform of Classroom Teaching Mode of Electronic Specialty for Application-oriented Undergraduate College
}

\author{
Hongli Zhu \\ School of Information and Electronic Engineering, Zhejiang University City College, Hangzhou \\ 310015, China; \\ zhuhl@zucc.edu.cn
}

\begin{abstract}
The reform of classroom teaching model has become a hot area. Application-oriented undergraduate refers to the application-oriented positioning for the school, rather than scientific research for the positioning of undergraduate colleges. For an application-oriented undergraduate university, the quality of personnel training is the most important, so that students in the classroom can efficiently learn theory and practice knowledge is the key to improving the quality of talent. In view of the main problems in the current classroom teaching, combined with the advantages of lectures and discussion classes, the use of PAD teaching method, emphasizing the students after school self - learning, effectively enhance the initiative of students to learn. The results show that teaching effect is good.
\end{abstract}

Keywords: Independent college; Teaching methods, Application-oriented

\section{应用型本科电子类专业课堂教学模式改革}

\author{
朱红丽 \\ ( 浙江大学城市学院、信息与电气工程分院, 浙江 杭州 310015)
}

摘要: 从当代教育改革的总体趋势来看, 课堂教学模式的改革已经成为一个热点领域。应用型本科是指以应用型为办学 定位，而不是以科研为办学定位的本科院校，应用型本科教育对于满足中国经济社会发展，对高层次应用型、技术型人才需 要以及推进中国高等教育大众化进程起到了积极的促进作用。对于一所应用型本科高校来说, 人才培养质量是重中之重, 能 让学生在课堂上高效的学习理论与实践知识是提高人才质量的钥匙。针对当前课堂教学中存在的主要问题, 结合讲授式课堂 与讨论式课堂的优点, 利用对分课堂的课堂教学改革新模式, 强调学生在课后自主学习, 进行个性化的内化吸收。有效地增 强了学生学习的主动性, 教学效果良好。

关键词: 对分课堂; 应用型本科; 课堂教学; 模式

中图分类号: G712 文献标志码: A

引言

大学课堂是大学教育教学活动的主要场所, 目前, 大学课堂教学的主导模式依然是 “讲授式教学”, 是一种以教师为主导、学生被动跟随的教学模式。

这种模式获得好的教学效果的前提在于教师的讲课风格幽默风趣、氛围轻松、表演性强, 且传授的课 程内容丰富新颖, 学生较难通过其他途径获得。而电子类专业课程内容较为枯燥严肃, 并不具备较强的表 演性。

随着网络技术的发展, 学生获取知识的途径越来越多, 不可避免地带来如课堂缺课率高、学生上课玩 手机等问题, 缺乏学习积极性和主动性也日益凸显。厘清课堂教学中的师生角色关系及其职责, 改革大 学课堂教学模式, 是提升大学教育教学质量的内在要求。

\section{1 课程教学中存在的问题}


大学课堂常常三课时连续上课, 对于独立学院的学生来说, 学习主动性及意愿不足, 很难保持如此长 时间的注意力。作为教师而言, 为了将教学大纲内的知识悉数教授给学生, 也无法全程做到幽默、风趣地 演绎公式、定理等。

此外, 随着高校对外合作交流的深入, 引进了大量优秀的教科书。但在使用的过程中, 如果教师在课 堂上是按书来讲, 学生反而会觉得教师照本宣科、水平不高; 如果不按书教, 教师需要呈现替代材料或 增加内容, 效果未必好, 还会增加学生的学习负担。

再者, 传统教学以教师为主导, 引导学生配合, 吸收教师讲授的内容, 按教师的思路去思考。属于教 师单向灌输, 学生被动跟随。对学生而言, 并不能主动参与知识构建、尝试问题解决, 对思维能力和探索 精神的培养无法落到实处。

针对传统教学的一个改革方向是采用讨论式教学。讨论式教学需要教师深度参与, 不适合大班教学。 由于讨论的开放性特点, 如果按学生的思路展开, 极易偏离教学内容, 影响学习的系统性; 如果教师按教 材内容去引导, 学生的自主性学习可能沦为表面现象。

\section{2 “对分课堂” 教学模式的核心理念与实施过程}

现代高校教学越来越重视和强调引导学生主动地参与到学习过程中, 强化教师与学生之间交互式的教 与学的过程以提高教学成效。基于这一理念, 复旦大学心理系的张学新教授提出 “对分课堂” 教学模式。 “对分课堂” 针对传统教学模式的不足, 提出了基于建构主义教育理念的新型课堂教学模式, 在教师讲授 的基础上, 强调学习的自主建构性和教学的情景互动性, 把教师的 “讲” 与 学生的 “学” 和 “思” 结合 起来, 是建构主义与传统教学模式的独特结合。

“对分课堂” 在具体操作上是指把课堂的时间一半分配给教师讲授, 一半分配给学生讨论, 注重先教 后学, 教师讲授在先, 学生学习在后, 强调生生互动、师生互动, 鼓励自主性学习。

“对分课堂” 把教学分为相互联系的三个过程, 分别为教师的课堂讲授 (Presentation) 即教师在课堂 上对教学内容进行精讲, 帮助学生了解知识的框架, 了解学习的重点难点; 学生课后的内化吸收 (Assimilation) 即学生在课堂教学之后通过阅读教材或其他材料将知识内化为个人的经验, 是学习和思考 相结合的过程; 学生的课堂讨论 (Discussion), 带着课后的自学和思考结果与班级的学生进行交流, 可分 为小组讨论和组间讨论。用三个环节的英文首字母命名, 也可简称为 PAD 课堂。把讲授和讨论错开, 让学 生在中间有一定的时间自主安排学习, 进行个性化的内化吸收, 以讨论和作业的形式强化学习的成果是 “对分课堂” 的关键创新。

“对分课堂” 通过 “对分” 的形式克服讲授式教学中学生被动接受的现象, 引导学生参与课堂教学活 动, 使学生通过听课、自学、作业、讨论等方式对知识进行积极建构, 增加教学中的师生交流与生生沟 通, 使教师和学生在教学中都发挥作用, 从而提高教学质量。

与其他类型的课程相比, 软件基础课程要让学生掌握一些必要数据结构、操作系统知识, 还要让学生 对各种算法融会贯通, 并能够应用于软件开发过程中。考虑到学生的学习情况和该课程的特性, 本次课堂 教学改革将 “对分课堂” 教学模式应用于课程教学中, 探索 “对分课堂” 教学新模式, 以提高课程的教 学效果。

\section{3 软件基础课程的 “对分课堂” 教学模式探索}


《软件基础》每周上课一次, 连续 3 节, 每节课 45 分钟。拟开展 10 周的对分课堂。根据对分课堂 的原理和操作步骤, 前一半时间教师对新内容框架、基本概念、重点难点进行讲解, 学生认真听讲。后一 半时间由学生分组讨论上周讲授内容, 温习课本知识、列出内容提纲、分享学习体会, 并互相解答疑难。 交流讨论环节的大致内容包括组内交流、组间交流、全班交流、教师抽查、总结报告（作业）展示、老师 总结。课后, 学生需要阅读课本及教师提供的大量参考资料, 自行内化吸收上次课内容并完成 $1^{\sim} 2$ 道综合 性较强, 有一定难度和深度的开放性题目, 为下次课深入、有意义的分组讨论做准备。

具体地，第一周上课课堂时间不对分，本周 3 节课由教师讲授第 $1^{\sim} 2$ 章内容，学生认真听讲。下课 后学生复习、内化吸收这两章内容, 写出内容提纲、并解答课后习题, 第 2 周上课前将作业提交至 BB 平 台。第 2 周即开启对分教学模式: 第 1,2 节课, 教师继续讲授第 2 章内容, 并预留一个小知识点供学生 课后自行学习, 要求学生课后认真复习并学习新知识点, 撰写内容提纲、并完成课后习题, 作为作业于第 3 周上课前提交。第 3 节课, 学生每 4 5 人一组开展讨论, 温习第一次课内容、分享体会、互助解答疑难, 并交流教科书上复习题的解答步骤。最后教师与学生互动、抽查, 对学生存在的疑难进行解答, 并展示、 点评优秀作业。第 3 到第 10 周的模式与第 2 周类似: 前一半时间教师讲授下一个知识点, 后一半时间学 生讨论上周讲授内容或自学的知识点（内容提纲十课后习题）。

交流讨论环节的大致时间安排如下：组内交流（20 分钟）、组间交流（5 分钟)、全班交流（5 分钟)、 教师抽查 (5 分钟)、读书笔记 (作业) 展示 (5 分钟)、老师总结 (5 分钟)。

\section{4 结论}

实施对分模式后, 学生的课堂表现与传统课堂相比有了明显变化, 具体表现在:

学生讨论积极, 课堂主动参与意识增强。上课后, 学生能按照要求完成作业, 并带着作业到课堂上进 行讨论。在讨论中不仅积极参与小组讨论, 而且在小组总结环节也针对一些问题积极发言。

学生作业认真, 深层次、延伸性问题逐渐增多。课堂外, 学生认真复习 ppt 课件, 仔细阅读教材和推 荐阅读材料, 思考和巩固, 并从中发现问题、查阅资料, 得到启发后再进行讨论, 整个过程收获很大。对 编程语言的恐惧心理也在逐渐减退, 敢读敢改程序的能力在慢慢培养, 对感兴趣的算法会积极编程实现。

促进教师深化专业素养，紧跟科研前沿。现代大学生的思维非常活跃，一旦他们认真对待某些任务， 将会迸发出教师意料之外的创意、假设和问题。教师在备课阶段必须自我挑战, 深挖教材内容、紧跟科研 前沿, 让自己具备扎实的基本功。学生讨论后, 教师要回答仍然存在的问题, 这需要教师课后查阅更多的 参考书和网络资源，甚至必须阅读国外原版教材或跟踪最新的研究进展。

\section{References}

[1] Xuexin Zhang. PAD Class: A New Attempt in University Teaching Reform [J]. Fudan Education Forum. 2014, 12(5) (in Chinese)

[2] Shige Wang, Mingxian Huang. Potential Applications of PAD Class in Teaching College Chemistry [J]. Guangzhou Chemical Industry. 2016, 44(5) (in Chinese)

[3] MICHELE M. Teaching at Stanford: an introductory handbook [M].Denver: The center for teaching and learning, Stanford University. 2007 
[4] CROUCH C H, MAZUR E. Peer Instruction: Ten years of experience and results [J].American Journal of Physics, 2001, 69(9)

[5] Qing Kong. On Classroom Teaching Methods in Higher Education Based on Information-Flowing Direction. Journal of Henan University of Technology (Social Science). 2010, 6(3) (in Chinese)

[6] Liu Yongfeng, et al. The Misconception of Bilingual Teaching in Higher Education and Its Solutions [J]. Research in Higher Education of Engineering. 2006(2).

[7] Guo Qiang. Problems and Countermeasures for Bilingual Education in Local Universities [J]. Journal of Shaoguan University. February, 2006(2)

[8] Jiang Jing. Discussion on Bilingual teaching of Economics and Management courses in Colleges and Universities [J], China Adult Education. June, 2006(6)

[9] Liang Yu. Status of Bilingual Teaching in Colleges and Universities and the Countermeasures [J], Heilongjiang Education (Higher Education Research \& Appraisal). 2006(5).

[10] Yao Xiaoyan, et al. Discussion on the Construction of the Teaching Materials for the Bilingual Teaching [J]. Sci / Tech Information Development \& Economy.P16, 2006(7).

[11]Li Xiaodi. The Current Situation of Bilingual Education in Singaporean Colleges and Universities and Its Inspiration to Chinese Education [J]. Modern Education Science. 2004(2).

[12] Yu Yongsheng. On the Countermeasures for Improving Bilingual Teaching in Specialty of Finance [J]. Journal of Mudanjiang College of Education. 2006(3). 